\title{
Teacher Perspective on the Reality of Organizational Justice for Public Schools in Kuwait
}

\author{
Sultan Ghaleb Aldaihani, Shaima Essa Alansari \\ Kuwait University, Kiefan, Kuwait
}

\begin{abstract}
This study aimed to identify the degree of organizational justice perceived by teachers in public education schools of Kuwait in relation to experience, nationality, teaching level, and education district. The study sample included 1,203 teachers representative of all teaching levels found in Kuwaiti schools. The study employed a descriptive approach, using a two-section questionnaire to measure the teachers' perspectives on the existing degree of distributive and interactional justice within the educational system. The validity and reliability of the questionnaire were verified before its application. The study data was analysed by using a set of statistical methods including one-way analysis of variance, $t$-test, and Pearson correlation. The results indicated that non-Kuwaiti teachers perceive a greater degree of organizational justice than teachers in the Kuwait public education system. Distributive and interactional justice received a medium rating, with a correlation degree of 536.
\end{abstract}

Keywords: organizational justice, procedural justice, distributive justice, interactional justice, Kuwaiti public schools

\section{Introduction}

Every school has targets that must be achieved and school staff must be selected who can efficiently achieve these targets. It is thus of interest to identify the factors that push employees to make the greatest efforts to raise their performance level and efficiency. In this study, we address the subject of organizational justice and its impact on the ability of educational institutions to provide a supportive environment for teachers. Previous studies have found that achievement of justice within the school system leads to improved performance (Hoy \& Tarter, 2004).

Educational institutions are concerned with applying organizational justice in order to achieve important administrative gains, such as strengthening the professionalism of teachers (Dipaola \& Guy 2009). A number of factors demand the study of organizational justice, first and foremost being the recognition that justice is a social phenomenon involving all aspects of life, and secondly, that the human element is the most important and valuable asset of any institution.

The concept of organizational justice is relatively recent. This theory emerged and was developed by Adams in 1963, in his study of equity theory as one of the practices associated with human resources management. In equity theory, individuals not only make efforts with an expectation of corresponding returns in the form of good salary and other privileges, but also to experience the sensation of justice in viewing these

Sultan Ghaleb Aldaihani, Ph.D., associate professor, Department of Educational Administration and Planning, College of Education, Kuwait University.

Shaima Essa Alansari, Master, student, Department of Educational Administration and Planning, College of Education, Kuwait University. 
returns as a reward for their efforts in the form of output. In evaluating organizational fairness, a comparison process focuses on the returns to individuals in exchange for their output and that of their colleagues, which is called distributive justice (Erkutlu, 2010).

In the 1980s, the tendency of organizational justice moved in another direction, interactional justice. In other words, there is a kind of social and human communication among employees that measures justice in terms of respect for employees, fairness of decisions, adherence to regulations and laws, and policy implementation (Karakose, 2014).

\section{The Origins of Justice}

In ancient times, philosophers were interested in the subject of justice as a prescriptive means of clarifying justice practices within the scope of public morality. More recently, administrative scientists have approached organizational justice not as an objective or prescriptive moral concept, but in a descriptive way in order to understand employee awareness of organizational justice and the effects of organizational justice on organizational operations and success. In other words, one employee may believe that a decision or regulatory action shows partiality, while another may believe it to be objective and fair (Cropanzano, Bowen, \& Gilliland, 2007). Others, such as Cropanzano et al. (2007) and AlNassani and Alyousfi (2002) have approached the subject from the perspective of instilling and maintaining justice at an organizational level by studying the impact of variables in leadership styles as they relate to hiring, performance appraisal, reward and penalty systems, and conflict management.

In general, organizational justice is the perception of individuals of the fairness of decisions made and acted upon by the organization, the equity of the procedures employed in the decision-making process, and the quality of personal treatment received by employees and managers (Coetzee, 2005)—in other words, and the awareness of staff and administrators of the three aspects of organizational justice: distributive, procedural, and interactional (Altamna \& AlShawy, 2011).

Alanzy (2012) put forth two hypotheses regarding what is needed in order for organizational justice to be perceived by the individual:

1. Individuals continuously measure the ratio between their outputs to the organization and the inputs received from the organization. In applying this to the educational environment, we can say that teacher's awareness of organization justice is based on a comparison of his or her outputs in job performance, experience, work hours, and lack of absenteeism with his or her inputs in terms of rewards, as well as the equality or inequality in distribution of administrative burdens.

2. Essentially, the individual is driven by perceptions of lack of justice. The existences of just conditions result in a balance for the person. But, if justice does not exist, the person will feel anger or guilt, and a state of unbalance.

Niehoff and Moorman (1993) delineated three types of organizational justice:

1. Distributive justice: The organizational inputs obtained by employees in return for their work, based on the principle of equality (Niehoff \& Moorman, 1993);

2. Procedural justice: The processes used by the organization to determine what inputs employees receive (Cropanzano et al., 2007);

3. Interactional justice: The fairness of the communications used by the organization in carrying out formal justice procedures, as represented by such factors as courtesy, respect, trust, frankness, and assignment of the importance to employee interests (Dorars, 2008). 
Interactional justice can be further broken down (Cropanzano et al., 2007):

a. Informational justice: The fairness of the information relayed to employees and the perceived justification of communications about administrative decisions;

b. Interpersonal justice: The quality and manner of personal treatment for the individual during the decision-making processes.

Alanzy (2012) found that it is possible to enhance the awareness of interactional justice by holding training courses in communication and treatment skills for managers and department heads. With these skills, administrators are able to provide explanations and sufficient justification for evaluations and administrative decisions regarding the teacher. The employee who feels that the organization provides equitable procedural, distributive, and interactional justice tends to feel a high level of commitment toward the organization (Al-Saud \& Sultan, 2009).

\section{The Study Problem}

Although many studies discuss the subject of organizational justice, the main focus has been on the private sector. Further understanding of the impact of organizational justice in the public sector, especially education, is critical because of its potential impact on building communities. It is necessary to communicate with employees, according to the concept of organizational justice, because it is one of the most important aspects of school management, reflecting on the entire educational process (Devonish \& Greenidge, 2010).

This study complements previous researches efforts that have linked the participation of teachers in decision-making to procedural justice and productivity. A study conducted in Kuwaiti secondary schools concluded that participation of teachers in decision-making regarding technical and administrative processes addressing procedural components increased among those who perceived organizational justice in the public school system (Alanzy, 2012).

The problem of this study can be formulated in the following questions:

1. What is the level of organizational justice in terms of distributive and interactional justice in Kuwaiti public schools from the perspective of teachers?

2. Do the teachers' opinions vary according to the following factors?

a. Educational district (Al-Asimah, Hawalli, Al-Farwaniya, Al-Ahmadi, Al-Jahra, or Mobarak Al-Kabeer);

b. Teaching experience (Less than 5 years, 5 to less than 10 years, 10 to 15 years, or more than 15 years);

c. Level taught (Kindergarten, primary, intermediate, or secondary);

d. Nationality (Kuwaiti or non-Kuwaiti).

3. Is there a statistically significant correlation between the questionnaire axes: distributive justice and interactional justice?

\section{Study Objectives}

The study had five objectives:

1. Identify the reality of distributive justice in the public education schools of Kuwait;

2. Identify the reality of interactional justice in the public education schools of Kuwait;

3. Identify the impact of the following demographic factors on teachers' perception of organizational justice: educational qualifications, teaching level, and the number years in service;

4. Identify the relationship between distributive justice and interactional justice in the public education schools of Kuwait; 
5. Provide recommendations based on the study's findings.

\section{The Importance of This Study}

A study by Almathkour (2011) that investigated organizational loyalty among faculty members at Kuwait University recommended studying the degree of organizational justice to be found in other educational sectors in Kuwait. The importance of this study derives from the importance of organizational justice in educational institutions in Kuwait. In practice, the educational sector is a vital contributor to the country's progress. The study population as represented by teachers constitutes the basic element of any educational system. This research represents a modest addition to the Arabic library by providing insight into existence of organizational justice in the public education system of Kuwait as perceived by its teachers.

The special importance of the human element as a factor in the production system of this sector lends significance to the study of organizational justice within the system. It is expected that this study will provide data and information for the managers of public-education schools in Kuwait to guide them in their practice of organizational justice as well as serving for a springboard for further research on this issue.

\section{Study Terms}

Organizational justice. Organizational justice is defined here as the perception of employees regarding the practice of justice in the organization and encompasses reactions to the situations in which it is perceived that justice is not achieved (Cropanzano \& Greenberg, 1997).

Procedural justice. Procedural justice can be defined as the perception of fair treatment in the administration of organizational justice. This aspect of justice relates to resource allocation and addresses such factors as working hours, quotas, the rewards, advancement opportunities, and in-service training. In the school setting, procedural justice includes the perception of teachers whether they receive rewards commensurate with their efforts and in comparison with the efforts of colleagues.

Distributive justice. Distributive justice is concerned with for the fair distribution of rewards in return for employee outputs of the colleagues, especially in terms of salaries and in-kind benefits (Cropanzano et al., 2007).

Interactional justice. Interactional justice is defined here as the perception of the quality of the communications from decision makers to employees regarding explanation and implementation of formal justice procedures (Yilmaz, 2010).

\section{Previous Studies}

\section{Arabic Studies}

Al-Gendyand Al-Banna (2007) analysed the psychological dimensions of three methods of occupational performance evaluation and their relation to the perception of organizational justice by employees of educational institutions. The study was confined to a representative sample of employees in primary and secondary level educational institutions in Alexandria province. The study found that the methods used in evaluating occupational performance had an impact on the employees' perceptions of organizational justice within the institution.

Al-Atwi (2007) aimed to identify correlations between organizational justice and the contextual performance of a sample representing the faculty at the Al-Qadisiya University, Economic and Management College. The results confirmed the researcher's hypothesis that organizational justice complements both contextual and task performance to improve the quality and quantity of work. Analysis of the results demonstrated a positive 
correlation between most organizational justice and contextual performance dimensions, indicating that individual contextual performance increases with the perception of higher levels of organizational justice, especially procedural justice.

Al Fadly and Alanzy (2007) sought to identify the relationship of such elements as trust in leadership and procedural and interactional justices as well as the impact of a set of organizational and personal variables (gender, educational qualification, service years, the leadership's importance to the employees, and trust in management) of the governmental management sector in Kuwait. The study sample consisted of 182 employees working in six Kuwaiti civil service agencies. It found that low sense of organizational justice among female workers as well as an inverse relationship between educational qualifications and duration of experience and individual perception of organizational justice.

AbuTayeh (2012) aimed to analyse the impact of employees' perception of organizational justice on organizational citizenship behaviour in government ministries in Jordan. This study hypothesized a positive impact of organizational justice distributive, procedural, and communication dimensions on the organizational citizenship behaviour dimensions of civility, sportsmanship, and conscience. The responses of 326 employees in Jordanian Ministry Centres showed that the employees’ perception of organizational justice with its all dimensions was above average, while organizational citizenship behaviour with its all dimensions was high. The study concluded that employee perception of procedural justice has a greater role in influencing organizational citizenship behaviour, compared with the other two dimensions of organizational justice, and recommended the strengthening of organizational justice and citizenship values among Jordanian government ministers.

Alanzy (2012) aimed to identify the climate of organizational justice, including the three dimensions distributive, procedural, and interactional, perceived by teachers of a public district of Kuwait. The study sample consisted of Kuwaiti and non-Kuwaiti teachers at three academic levels. A descriptive approach was used to test the impact of demographic variables (gender, nationality, education level, qualification, and seniority) on teacher evaluation of the justice climate, found that there was a perception of a high degree of justice in all three dimensions among teachers, with interactional justice receiving the highest rating, followed by distributive and procedural justices at lower and equivalent levels. The study provided a variety of suggestions for improving the climate of justice in the school setting.

Al Obeidy (2012) conducted a field study in the Iraqi Ministry of Higher Education and Scientific Research which aimed to determine the nature of the relationship and impact between organizational justice and organizational commitment within the ministry. The research data indicated a strong correlation between the variable of interactional justice and trust in and commitment to the organization. The researcher recommended review of the organizational environment with a view toward any needed adaptations.

\section{International Studies}

Titrek (2009) studded levels of organizational justice in Turkish schools. The sample comprised 1,016 staff selected from seven schools and employed a scale measuring perception of fairness of interpersonal treatment. The results showed that the greatest shortcomings in organizational justice behaviour in Turkish schools related to the behaviour of managers toward employees. Gender, experience, position, and marital status also had a significant effect on employee perception of fairness within the organization. The study recommended standardization of policies and procedures in order to ensure equity for all employees, education of managers regarding fair management practices, and eradication of any factors that generate a "fear culture." 
Yilmaz (2010) described the perceptions of high school teachers about organizational justice as modified by gender, age, seniority, specialization, and education background in a sample of 222 high school teachers in Kütahya, Turkey. The study participants were found to have overall positive perceptions about organizational justice in their schools, which varied with age and seniority but were consistent across genders and educational backgrounds.

Erkutlu (2010) sought to identify the relationship between the organizational citizenship behaviour and organizational justice. The sample consisted of faculty members at 10 Turkish governmental universities. The study found a strong relationship between interactional justice and citizenship behaviour in organizations that give greater respect to individuals within the system and a weak relationship between distributive and procedural justices and citizenship behaviour in organizations that give precedence to team orientation. The study concluded that fostering respect and fairness, understanding organizational culture, addressing needs of individuals, and providing a supportive work environment are all elements in the success of leaders.

Karakose (2014) studied the relationship between organizational justice and job satisfaction among high school teachers in Turkey. The study employed a descriptive approach and concluded that organizational justice has a great impact on employee job satisfaction. The perceptions of high schools teachers regarding organizational justice were below the middle level. The study recommended efforts to establish organizational justice with regard to promotion, decision-making, equality, and transparency.

\section{Comparison With Previous Studies}

The subject of the current study is also addressed in the studies of Abu-Tayeh (2012), Alanzy (2012), Al-Atwi (2007), Al Fadly and Alanzy (2007), Al-Gendy and Al-Banna (2007), AlObeidy (2012), Erkutlu (2010), Karakose (2014), Titrek (2009), and Yilmaz (2010). Most of the previous studies used a correlative descriptive approach to measure the impact or the relationship between organizational justice and other variables. This study utilized as descriptive survey approach based on field study. It used a similar methodology to that of Alanzy (2012), AlFadly and Alanzy (2007), Titrek (2009), and Yilmaz (2010). Al Fadly and Alanzy (2007), Abu-Tayeh (2012), and AlObeidy (2012) used the population samples drawn from the general governmental sector. Al-Atwi (2007) and Erkutlu (2010) sampled universities; Al-Gendy and Al-Banna (2007) investigated schools in Alexandria; and Alanzy (2010), Karakose (2014), and Yilmaz (2010) sampled high schools. The current study took its sample population from all the provinces in Kuwait across all educational levels.

\section{Methodology}

This study used a descriptive survey method designed to describe the characteristics of the community studied (Murad \& Hadi, 2014).

This study is limited to an investigation of organizational justice and its dimensions. The geographical area included public education schools of all educational stages in the six educational districts of Kuwait. The study population was limited to teachers at all levels in the public education schools of Kuwait. The study was conducted in 2015.

The current study sought to get a representation sample of the Kuwaiti educational community by randomly selecting teachers from the six educational districts of Kuwait. A total of 1,203 teachers were included in the study. The demographics of the study sample are provided in Table 1. 
Table 1

Study Sample Demographics

\begin{tabular}{llcc}
\hline Variable & Type & Number & Percentage (\%) \\
\hline \multirow{2}{*}{ Nationality } & Kuwaiti & 971 & 80.7 \\
& Non-Kuwaiti & 232 & 19.3 \\
\hline \multirow{2}{*}{ Years of experience } & $<5$ years & 266 & 22.1 \\
& $5-10$ years & 327 & 27.2 \\
& $11-15$ years & 280 & 23.3 \\
& $>15$ years & 330 & 27.4 \\
\hline \multirow{3}{*}{ Teaching level } & Kindergarten & 157 & 13.1 \\
& Primary & 412 & 34.2 \\
& Middle & 364 & 30.3 \\
& Secondary & 270 & 22.4 \\
\hline \multirow{3}{*}{ Educational district } & Al-Asimah & 166 & 13.8 \\
& Hawalli & 217 & 18.0 \\
& Al-Farwaniya & 138 & 11.5 \\
& Al-Ahmadi & 341 & 28.3 \\
\hline Total & Al-Jahra & 142 & 11.8 \\
\hline
\end{tabular}

The majority of the teachers were Kuwaiti nationals (80.7\%, compared with $19.3 \%$ non-Kuwaiti). It is rare to find that non-Kuwaiti teachers at the kindergarten stage; small numbers may be found at the primary level, and the most teach at the middle and secondary levels.

The tool used for the study was a questionnaire comprised of two main sections. Section 1 collected demographic data, including the variable of nationality, years of experience, gender, teaching level, educational district, and educational qualifications. Section 2 addressed two main axes of organizational justice: distributive justice and interactional justice.

The questionnaire design was based on a review of the literature related to the research subject and the study methods applied to similar research in the educational field. Following preliminary formulation, the proposed questionnaire was reviewed by a number of faculties from various disciplines at Kuwait University, and their feedback was used to refine it. Standard statistical methods were employed to analyse and evaluate the responses to the questionnaire. A Likert-scale was used to measure the degree of agreement teachers expressed for each questionnaire item ( 1 = Agree; 2 = Neither agree nor disagree; and 3 = Disagree).

Cronbach's alpha was used to ensure reliability of the study questionnaire results (see Table 2).

Table 2

Study Questionnaire Alpha Values

\begin{tabular}{lcl}
\hline Section & Number of items & Alpha value \\
\hline Distributive justice & 7 & 0.740 \\
Interactional justice & 6 & 0.917 \\
Total & 13 & 0.881 \\
\hline
\end{tabular}

The following steps were used to carry out the study:

1. Identify the objectives of the research and their importance.

2. Configure a theoretical framework for the concept, defining the concept, its facets, principles, and applied educational forms. 
3. Investigate the literature regarding previous studies related to organizational justice.

4. Adopt a procedural definition for the concept to be studied in the educational field.

5. Develop a questionnaire that elicits answers to the study questions and verification of the tool and its stability.

6. Survey the study community and its characteristics.

7. Evaluate the answers of the study sample to the questionnaire, coding and analysing the results using the appropriate statistical methods.

8. Display the results of the study questions and discuss them in light of the theoretical framework, previous studies and the application to the field of study.

9. Provide suggestions and recommendations for further study and practice.

The Statistic Package for Social Science (SPSS) statistics software program was used to analyse the scale data by using the following tools:

a. Mean and standard deviation;

b. Percentage and frequencies;

c. One-way analysis of variance (ANOVA);

d. Pearson's correlation coefficient.

\section{Results}

Study Question 1: What Is the Level of Organizational Justice in Terms of Distributive and Interactional Justice in Kuwaiti Public Schools From the Perspective of Teachers?

Most teachers agreed that there was a middle level of organizational justice in the schools (see Table 3).

Table 3

Teacher Perception of Organizational Justice

\begin{tabular}{llll}
\hline Section & Arithmetic mean & Standard deviation & Approval degree \\
\hline Distributive justice & 1.9170 & 0.49210 & Middle \\
Interactional justice & 2.0262 & 0.62305 & Middle \\
\hline
\end{tabular}

The standard deviation for the answers was low, which indicates a high level of agreement and homogeneity among the sample despite its large size. The highest deviation of 0.62305 was found for interactional justice.

\section{Study Question 2: Do the Teachers' Opinions Vary According to the Following Factors: Educational District, Teaching Experience, Level Taught, and Nationality?}

Tables 4-7 show the results analysed using one-way ANOVA. As can be seen in Table 4, here was an absence of statistical significance for distributive justice axis and high statistical significance for interactional justice $(p<0.05)$ in regard to whether the teacher was Kuwaiti or non-Kuwaiti.

It is clear from Table 5 that there are statistically significant differences $(\mathrm{p}<0.05)$ for all axes of the education district variable. Scheffé's method was used to detect the dimensional differences, which indicated statistical significance for the capital (Al-Asimah) for distributive justice and for Al-Jahra for both distributive and interactional justice.

As can be seen in Table 6, statistically significant differences were found for both distributive and interactional justice for all teaching levels $(p<0.05)$. Scheffé's method was used to detect the dimensional 
differences, which indicated statistical significance for kindergarten for distributive justice and for the secondary level for the interactional justice.

Table 4

One-Way ANOVA: Nationality of Teacher

\begin{tabular}{llllll}
\hline Axis & Type & Average & $T$ value & Freedom degree & Significance level \\
\hline \multirow{2}{*}{ Distributive justice } & Kuwaiti & 1.9134 & -0.525 & 1,201 & 0.600 \\
& Non-Kuwaiti & 1.9322 & & & \multirow{2}{*}{0.000} \\
\hline \multirow{2}{*}{ Interactional justice } & Kuwaiti & 1.9952 & -3.550 & 1,201 & 0.000 \\
\hline
\end{tabular}

Table 5

One-Way ANOVA: Educational District Variable

\begin{tabular}{llrrlll}
\hline Axis & Contrast source & Squares sum & Freedom degree & Squares average & $F$ value & $\begin{array}{l}\text { Significance } \\
\text { level }\end{array}$ \\
\hline Distributive & Between groups & 5.039 & 5 & 1.008 & 4.217 & 0.001 \\
justice & Inside groups & 286.403 & 1,197 & 0.239 & & \\
& Total & 291.082 & 1,202 & & \\
Interactional & Between groups & 4.196 & 5 & 0.839 & 2.172 & 0.055 \\
justice & Inside groups & 462.413 & 1,197 & 0.386 & & \\
\hline
\end{tabular}

Table 6

One-Way ANOVA: Teaching Level Variable

\begin{tabular}{|c|c|c|c|c|c|c|}
\hline Axis & Contrast source & Squares sum & Freedom degree & Squares average & $F$ value & $\begin{array}{l}\text { Significance } \\
\text { level }\end{array}$ \\
\hline \multirow{3}{*}{$\begin{array}{l}\text { Distributive } \\
\text { justice }\end{array}$} & Between groups & 12.835 & 3 & & \multirow{3}{*}{18.436} & \multirow{3}{*}{0.000} \\
\hline & Inside groups & 278.247 & 1,199 & $\begin{array}{l}4.278 \\
0.232\end{array}$ & & \\
\hline & Total & 291.082 & 1,202 & & & \\
\hline \multirow{3}{*}{$\begin{array}{l}\text { Interactional } \\
\text { justice }\end{array}$} & Between groups & 9.931 & 3 & & \multirow{3}{*}{8.692} & \multirow{3}{*}{0.000} \\
\hline & Inside groups & 456.678 & 1,199 & 3.310 & & \\
\hline & Total & 466.609 & 1,202 & 0.381 & & \\
\hline
\end{tabular}

As can be seen in Table 7, statistically significant differences were found for both distributive and interactional justice for years of experience $(p<0.05)$. Scheffé's method was used to detect the dimensional differences, which indicated the statistical significance for teachers with five years of experience for both distributive and interactional justice.

Table 7

One-Way ANOVA: Years of Experience Variable

\begin{tabular}{llccccc}
\hline Axis & Contrast source & Squares sum & Freedom degree & Squares average & $F$ value & $\begin{array}{l}\text { Significance } \\
\text { level }\end{array}$ \\
\hline Distributive & Between groups & 3.483 & 3 & 1.161 & \multirow{2}{*}{0.002} \\
justice & Inside groups & 287.600 & 1,199 & 0.240 & & \\
& Total & 291.082 & 1,202 & & \\
Interactional & Between groups & 3.011 & 3 & 1.004 & 2.596 & 0.051 \\
justice & Inside groups & 463.598 & 1,199 & 0.870 & & \\
\hline
\end{tabular}




\section{Study Question 3: Is There a Statistically Significant Correlation Between the Questionnaire Axes: Distributive Justice and Interactional Justice?}

Pearson's correlation coefficient was used to evaluate the degree of correlation between distributive and interactional justice (see Table 8).

Table 8

Degree of Correlation Between Distributive and Interactional Justice

\begin{tabular}{lll}
\hline Axis & Distributive justice & Interactional justice \\
\hline Distributive justice & Pearson correlation coefficient 1 & 536 \\
& Significance level & 0.000 \\
Interactional justice & Pearson correlation coefficient 536 & 1.000 \\
\hline
\end{tabular}

\section{Discussion}

The current study aimed to identify the status of organizational justice in Kuwaiti public schools. The study concluded that from the perspective of teachers organizational justice does exist. The perceived level of interactional justice exceeded that of distributive justice by a narrow margin. Much statistical significance can be attributed to the demographic variables studied.

A significant relationship exists between non-Kuwaiti teachers and satisfaction about the level of interactional justice. This indicates a professional level of ethics and moral direction among school administrators as discussed by Alanzy and Alhajri (2015).

Statistical significance was also found to exist between the educational districts of the capital Al-Asimah and Al-Jahra and distributive justice. This is due to the fact that most of the non-Kuwaiti teachers prefer the geographical location of the capital.

The statistical significance found between the teaching level of kindergarten and distributive justice was an expected result due to the short working hours compared to the other levels and their salaries. Teachers at this level enjoy more freedom in tasks management, smaller class sizes, and fewer administrative tasks.

The significant correlation between interactional justice and the secondary level can be attributed to the focus of the school administration on the students' future at this level, which leads to greater support of and communication with teachers and a consequent perception of justice. These results are corroborated by Yilmaz 2010) perceptions of high school teachers regarding organizational justice.

The statistical significance between teachers with five years of experience and both distributive and interactional justice can be seen as stemming from the activity of the new teacher trying to build expertise and find encouragement from her subordinates.

In the end, we can see that there exists a direct relationship between distributive and interactional justice, which comes as a natural result of efforts to achieve full justice for all teachers. This conclusion is confirmed by AlObeidy (2012).

\section{Recommendations and Proposals}

The overall results of this study prompt the following recommendations and suggestions:

1. Conduct more field studies to identify the state of organizational justice in both public and private schools. 
2. Investigate prevalent procedural justice practices and their relation to distributive and interactional justice.

3. Explore the best methods for training administrators in the promulgation and execution of organizational justice in all its ramifications.

\section{References}

Abu Tayeh, B. (2012). The effect of organizational justice on organizational citizenship behaviour in government ministries centres in Jordan, Islamic University. Economic and Administrative Studies Journal, 20, 145-186. (in Arabic)

Alanzy, A., \& Alhajri, S. (2015). Idealism, relativity and its relation with some personal variables for the public education schools managers in Kuwait: A field study in the professional ethics. Journal of Educational and Psychological Studies, 29, 115. (in Arabic)

Alanzy, M. (2010). The relationship between teachers' participation in decision making, its job satisfaction and productivity: A field study of some high schools in Kuwait (Unpublished Ph.D. thesis, Menofia University). (in Arabic)

Alanzy, N. (2012). The organizational justice as perceived by teachers in the public education sector of the capital (Unpublished master's degree thesis, Kuwait University). (in Arabic)

Al-Atwi, A. (2007). Organizational justice effect on contextual performance. Al-Qadisiya Journal for Administrative and Economic Sciences, 9(3), 146-170. (in Arabic)

Al Fadly, F., \& Alanzy, A. (2007). The relationship between organizational justice and some organizational and demographic variables in the governmental bodies in the State of Kuwait. Arab Journal of Administrative Sciences, 14(1), 43-76. (in Arabic)

Al-Gendy, A. A., \& Al-Banna, A. E. (2007). The feel of organizational justice and it relationship with the evaluation of job performance and the awareness of the psychological dimensions of the educational environment. The Future of Arabic Education Journal, 13(47), 9-130. (in Arabic)

Almathkour, M. (2011). The organizational loyalty degree of the faculty members in Kuwait University. Journal of Educational and Psychological Studies, 5, 1. (in Arabic)

AlNassani, A. M., \& Alyousfi, M. (2002). Test the impact of organizational justice and trusts intermediate variables in the relation of transformational and reciprocity leadership with organizational citizenship behaviours. Research Journal of Aleppo University, 1, 3. (in Arabic)

AlObeidy, N. (2012). The organizational justice impact and its relation to the organizational commitment: A field study in Ministry of High Education and Scientific Research. Tikrit Journal for Economic and Administrative Sciences (Tikrit University), 8, 24. (in Arabic)

Al-Saud, R., \& Sultan, S. (2009). The degree of organizational justice among the heads of academic departments in the official Jordanian universities and their relationship allegiance organizational faculty members. Damascus University Journal, 25(1), 191-231. (in Arabic)

Altamna, M., \& AlShawy, A. (2011). The level of practice of organizational justice in the Iraqi public sector. Egypt: The Arab Organization for Administrative Development. (in Arabic)

Coetzee, M. (2005). The fairness of affirmative action: An organisational justice perspective (Doctoral thesis, University of Pretoria).

Cropanzano, R., Bowen, D. E., \& Gilliland, S. W. (2007). The management of organizational justice. Academy of Management Perspectives, 21, 34-48.

Cropanzano, R., \& Greenberg, J. (1997). Progress in organizational justice: Tunnelling through the maze. International Review of Industrial and Organizational Psychology, 12, 317-372.

Devonish, D., \& Greenidge, D. (2010). The effect of organizational justice on contextual performance, counterproductive work behaviors, and task performance: Investigating the moderating role of ability-based emotional intelligence. The International Journal of Selection and Assessment, 18(1), 75-86.

Dipaola, M., \& Guy, S. (2009). The impact of organizational justice on climate and trust in high schools. Journal of School Leadership, 19, 382-405.

Dorars, O. (2008). The organizational justice and its relation with some contemporary administrative directions. Syria: Alradwan House. (in Arabic)

Erkutlu, H. (2010). The moderating role of organizational culture in the relationship between organizational justice and organizational citizenship behaviours. Leadership \& Organization Development Journal, 32(6), 532-554. 
Hoy, W. K., \& Tarter, C. J. (2004). Organizational justice in schools: No justice without trust. International Journal of Educational Management, 18(4), 250-259.

Karakose, T. (2014). The empirical study of organizational justice and job satisfaction for high school teachers in Turkey. Pakistan Journal of Statistics, 30(6), 1243-1250.

Murad, S., \& Hadi, F. (2014). Scientific research methods, its designs and procedures. Cairo: Modern Printing House. (in Arabic)

Niehoff, B. P., \& Moorman, R. H. (1993). Justice as a mediator of the relationship between methods of monitoring and organizational citizenship behavior. Academy of Management Journal, 36(3), 527-555.

Titrek, O. (2009). Employees' organizational justice perceptions in Turkish schools. Social Behavior and Personality: An International Journal, 37(5), 605-620.

Yilmaz, K. (2010). Secondary public school teachers’ perceptions about organizational justice. Educational Sciences: Theory and Practice, 10(1), 603-616. 